\title{
Fluxo escolar de alunos com deficiência em um município: o que revelam os dados oficiais
}

\author{
School flow of students with disabilities in a municipality: what the official \\ data reveal
}

Flujo escolar de alumnos con discapacidad en un municipio: lo que revelan los datos oficiales

\author{
* Ana Carolina Macalli \\ Mestre na Universidade Federal de São Carlos (UFSCar), São Carlos, São Paulo, Brasil. \\ anacarolinamacalli@hotmail.com
}

\section{** Taísa Grasiela Gomes Liduenha Gonçalves}

Professora doutora na Universidade Federal de Minas Gerais (UFMG), Belo Horizonte, Minas Gerais, Brasil. taisaliduenha@gmail.com

\section{${ }^{* * *}$ Katia Regina Moreno Caiado}

Professora doutora na Universidade Federal de São Carlos (UFSCar), São Carlos, São Paulo, Brasil. caiado.katia@ufscar.br

Recebido: 21 de julho de 2017

Aprovado: 5 de março de 2018

\section{RESUMO}

O objetivo desta pesquisa foi analisar o fluxo escolar dos alunos com deficiência em um município do interior paulista. Para isso, foi realizado um levantamento dos dados oficiais do município divulgados no Censo Demográfico de 2010. Em seguida, analisaram-se os Microdados de Censo da Educação Básica, disponibilizados pelo Instituto Nacional de Estudos e Pesquisas Educacional Anísio Teixeira (INEP), do Ministério da Educação, referentes às matrículas de alunos com deficiência entre 2007 a 2011. Desde 2003, o Ministério da Educação mantém o Programa "Educação Inclusiva: Direito à Diversidade", que visa a transformar os sistemas educacionais em inclusivos, por meio de formação promovida por um município polo aos municípios que compõem sua área de abrangência - oferecida a gestores e educadores. A escolha do município teve dois critérios: pertencer à região de abrangência do município-polo de São Carlos e apresentar o menor Índice de Desenvolvimento Humano (IDH) dentre os municípios da abrangência. Os resultados mostram que grande parte dos alunos com deficiência no município apresenta o fluxo escolar interrompido. Com relação à implementação do Programa "Educação Inclusiva: Direito à Diversidade" e seus desdobramentos no município, fica claro que seu objetivo não 
DOI: $10.5902 / 198468628212$

foi efetivado, pois não conseguiu reverter os altos índices de defasagem idade-série, repetência e evasão escolar.

Palavras-chave: Educação especial; Indicadores educacionais; Fluxo escolar.

\section{ABSTRACT}

The aim of this research was to analyze the educational flux of disabled students in a municipality of São Paulo State. For this purpose, was verified official data from the Demographic Census in 2010. Next step, was analyzed the Microdata Basic Education Census, provided by Instituto Nacional de Estudos e Pesquisas Educacional Anísio Teixeira (INEP) and from the Ministry of Education, regarding the enrollment of disabled students between 2007 and 2011. Since 2003, Ministry of Education maintain the Project "Inclusive Education: Right to Diversity", whose goal is to change educational systems into inclusive ones by formation- promoted by a pole municipality for other that constituted the coverage areas- offered to managers and teachers. The choice of municipality had two criteria: being in the region of São Carlos pole municipality and having the lowest Human Developing Index among the selected municipalities. The results show that great part of analyzed disabled students had their educational flux interrupted. In relation to the implementation of the Project "Inclusive Education: Right to Diversity", it is clear that its goal was not achieved, because was not possible to revert the high index of discrepancy age-grade, failure and school evasion.

Keywords: Special education; Education indicators; Educational flux.

\section{RESUMEN}

El objetivo de esta investigación fue analizar el flujo escolar de los alumnos con deficiencia en un municipio del interior paulista. Se realizó un levantamiento de los datos oficiales del municipio divulgados en el Censo Demográfico de 2010. Posteriormente se analizaron los Microdatos del Censo de Educación Básica correspondientes a las matriculas de alumnos con deficiencia entre los años 2007 a 2011, disponibles en el Instituto Nacional de Estudios e Pesquisas Educacional Anísio Teixeira (INEP) del Ministerio de Educación. Desde el 2003, el Ministerio de Educación apoya el programa "Educação Inclusiva: Direito à Diversidade" que tiene como finalidad transformar los sistemas educativos en inclusivos, a través de la formación a gestores y educadores siendo promovida por un municipio extremo a los municipios que componen el área de cobertura. El municipio fue escogido conforme a dos criterios: pertenecer a la cobertura del municipio extremo de São Carlos y presentar el menor índice de desarrollo humano (IDH) entre los municipios de cobertura. Los resultados evidencian que gran parte de los alumnos con deficiencia presenta interrupción en el flujo escolar. Con relación a la implementación del programa "Educação Inclusiva: Direito à Diversidade" y sus desdoblamientos en el municipio, queda claro que su objetivo no fue 


\title{
DOI: $10.5902 / 198468628212$
}

ejecutado, pues no logró revertir los altos índices de desfase edad-año, repitencia y evasión escolar.

Palabras clave: Educación especial; Indicadores educacionales; Flujo escolar.

\section{Introdução}

Em 1996, a Lei de Diretrizes e Bases da Educação Nacional afirmou o direito de o aluno com deficiência frequentar, preferencialmente, a escola regular. Concernente aos organismos internacionais, o Brasil assumiu as diretrizes da Educação Inclusiva, proclamadas na Declaração de Salamanca (1994) e reafirmadas na Convenção Internacional dos Direitos da Pessoa com Deficiência (ONU, 2007), promulgadas como emenda constitucional no Brasil pelo Decreto 6949, 2009.

O Ministério da Educação criou em 2003 o Programa "Educação Inclusiva: Direito à Diversidade", cujo objetivo final era

\begin{abstract}
efetivar a transformação dos sistemas educacionais em sistemas educacionais inclusivos, tendo como princípio, a garantia do direito dos alunos com necessidades educacionais especiais de acesso e permanência, com qualidade, nas escolas regulares. (BRASIL, 2005, p.9)
\end{abstract}

No período de 2003 a 2007, o Programa atingiu 5.564 municípios e formou 94.695 profissionais da educação ${ }^{1}$. Pesquisadoras da área analisaram esse Programa e apontaram críticas, tais como: relações de poder entre os sistemas públicos e privados que promovem o atendimento dos alunos da educação especial; ausência de financiamento, o que impossibilita a divulgação do conhecimento por parte das gestoras nos municípios abrangentes; ideias divergentes e conflituosas sobre o conceito de inclusão escolar; dentre outros aspectos (CAIADO; LAPLANE 2009). No entanto, em 2017, o Programa permanece publicado no site do Ministério, o que sugere sua vigência.

Dados sobre matrículas apresentados na Política Nacional de Educação Especial na Perspectiva da Educação Inclusiva (MEC, 2008a) mostram que houve aumento de 1.377\% no número de matrículas de alunos da Educação Especial em escolas regulares. Em 1998, foram 43.923 matrículas e, em 2013, foram 648.921.

\footnotetext{
${ }^{1}$ Informação disponível no site do MEC. Disponível em <http://portal.mec.gov.br/index.php?option=com_content\&view=article\&id=250\&ltemid=826>. Acesso em: 26 jun. 2017.
} 


\section{DOI: $10.5902 / 198468628212$}

Entende-se que o direito à escolarização compreende matrícula, permanência e apropriação do conhecimento escolar. Diante desses dados, inúmeras perguntas podem surgir, dentre elas: Os alunos com deficiência cadastrados no Censo Escolar permanecem na escola? Concluem as etapas de ensino? Apropriam-se do conhecimento escolar?

Neste artigo apresentaremos um estudo ${ }^{2}$ sobre o fluxo escolar dos alunos com deficiência, no período de 2007 a 2011, num determinado município no interior do estado de São Paulo. Para estudar o fluxo escolar nos microdados ${ }^{3}$ do Censo Escolar, elegemos focar este estudo em um município de pequeno porte, o que possibilitou identificar cada aluno cadastrado e acompanhar seu percurso a partir de um trabalho de análise minucioso.

Alavarse e Mainardes (2010, p.1) afirmam que "fluxo escolar indica a progressão de alunos, em determinado nível de ensino, em relação à sua condição de promovido, repetente ou evadido". Optou-se por trabalhar com o fluxo escolar, que, por estar relacionado ao acesso e à permanência na escola, possibilitaria compreender as taxas de transição dos alunos com deficiência na Educação Básica.

Lavarse e Mainardes (2010, p.2) destacam que as taxas de transição abrangem promoção, repetência e evasão, indicando como os alunos transitam de uma série para outra ou de um ano para o outro. Os autores afirmam que "o sistema educacional brasileiro costuma ser considerado como um sistema excludente e ineficiente, ou seja, acolhe a maioria da população em idade escolar, mas não garante a todos os alunos a permanência e a progressão no sistema escolar".

Nas palavras de Ferraro (2008, p. 275):

[...] o direito à Educação integra o conjunto dos direitos sociais [...] fundamentais da pessoa humana. Falar em dívida educacional pública significa duas coisas: primeiro, que a Educação se transformou num serviço público; segundo, que o Estado deixou de assegurar a determinadas pessoas ou grupos de pessoas o serviço público chamado Educação. É a conjunção dessas duas condições - a Educação entendida como serviço público e a não universalização ainda desse serviço - que coloca o Estado na condição de devedor e o cidadão na de credor de escolarização. Por escolarização, se deve

\footnotetext{
2 Estudo vinculado ao Projeto interinstitucional: "A escolarização de alunos com deficiência e rendimento escolar: uma análise dos indicadores educacionais em municípios brasileiros", desenvolvido pelo núcleo da UFSCar no período de 2011 a 2014 e financiado pelo Programa Observatório da Educação (CAPES/INEP, 2010).

3 "Os microdados do Inep se constituem no menor nível de desagregação de dados recolhidos por pesquisas, avaliações e exames realizados. As informações podem ser obtidas via download (...) em formato ASCII, e contêm inputs (canais de entrada) para leitura por meio dos softwares SAS e SPSS. Para abrir os arquivos, que estão em formato de compressão específico (.zip), é necessário o uso de algum programa descompactador". Disponível em: <http://portal.inep.gov.br/microdados>. Acesso em: 26 jun. 2017.
} 
DOI: $10.5902 / 198468628212$

entender não só o acesso, mas também a continuidade bem-sucedida na escola.

Ferraro (2008, p.275) nos alerta sobre o direito à educação envolvendo "a continuidade bem-sucedida na escola". Sobre isso, é importante destacar que finalizar uma etapa ou nível de ensino não garante que o aluno tenha se apropriado do conhecimento escolar proposto. O Observatório do Plano Nacional de Educação- PNE (2013) mostra que, entre a população brasileira na faixa entre 15 a 64 anos, 27\% "não conseguem realizar tarefas simples que envolvem a leitura de palavras e frases, ainda que uma parcela dessas pessoas consiga ler números familiares (números de telefone, preços etc.)". Assim, é importante ressaltar que, ao estudar o fluxo escolar, não estamos afirmando que os alunos que concluem etapas e níveis de ensino na idade esperada atingiram os níveis esperados de apropriação do conhecimento escolar.

A partir desse contexto, apresenta-se o município pesquisado e sua organização educacional, com destaque para a área da Educação Especial.

\section{O município}

O município pesquisado localiza-se no estado de São Paulo, a $306 \mathrm{~km}$ da capital, e tem 117 anos. Sua economia é voltada para o setor agropecuário. A população do município corresponde a 13.645 habitantes, em uma área territorial de 690,762 Km², sendo que 1.461 pessoas vivem em área rural e 12.184, em área urbana (IBGE, 2010).

Há, no município, 1.099 pessoas com deficiência permanente ${ }^{4}$. Destas, 415 são pessoas com deficiência visual; 136, com deficiência auditiva; 342, com deficiência motora; 206, com deficiência mental/intelectual (IBGE, 2010).

Com relação à desigualdade social, 8,69\% da população era considerada pobre em 2010 nesse município e 2,06\% extremamente pobre. O nível instrucional da população com 25 anos ou mais de idade do município correspondia a 13,48\% de analfabetos, 35,62\% com o ensino fundamental completo, $19,79 \%$ com o ensino médio completo e 5,01\% com o superior completo (ATLAS BRASIL, 2013).

Os indicadores de trabalho e renda apontam que, no ano de $2000,50,08 \%$ da população era vulnerável à pobreza e, em 2010, esse índice declina para $23,11 \%$. A renda

\footnotetext{
${ }^{4}$ Conforme o IBGE, com a autodeclaração, as pessoas afirmavam ter as seguintes características: não conseguem de modo algum ou têm grande dificuldade para exercer a capacidade visual, auditiva, motora, mental/ intelectual.
} 


\section{DOI: $10.5902 / 198468628212$}

per capita média do município cresceu 53,09\% nas últimas duas décadas, passando de $\mathrm{R} \$$ 387,57, em 1991, para $\mathrm{R} \$$ 487,27, em 2000, e R \$ 593,36, em 2010 (ATLAS BRASIL, 2013).

O município possui nove escolas de ensino regular, sendo que sete escolas são de dependência administrativa municipal, uma estadual e uma privada. Todas estão localizadas em áreas urbanas. Ainda sobre as escolas, seis ofertam o ensino fundamental, sendo que duas dessas escolas também ofertam a educação de jovens e adultos, duas ofertam educação infantil (creche e pré-escola) e uma oferta o ensino médio. A soma das matrículas de cada escola totaliza 3.202 matrículas na rede regular de ensino do município (INEP, DATA ESCOLA, 2012).

Com relação ao fluxo escolar nesse município, os dados mostram que, em 2010, a proporção era de $82,98 \%$ de crianças com 5 a 6 anos na escola. Na faixa etária de 11 a 13 anos, $86,08 \%$ frequentava os anos finais do ensino fundamental. Os indicadores mostram uma redução na proporção de jovens de 15 a 17 anos com ensino fundamental completo para 56,39\%, e de jovens de 18 a 20 anos com ensino médio completo para 35,51\%. Sobre a população de 6 a 17 anos, 91,66\% estava cursando, em 2010, o ensino básico regular com até dois anos de defasagem idade-série. Conforme os dados do censo escolar, o município não apresenta a modalidade de Educação Especial, que corresponde a classes ou instituições exclusivamente especiais. Também não oferta nenhum tipo de atendimento educacional especializado e não apresenta nenhum profissional formado ou especializado para atuar na escolarização de alunos com deficiência.

No entanto, os alunos com deficiência em condições de maior comprometimento são encaminhados para a Associação de Pais e Amigos dos Excepcionais (APAE) da cidade vizinha, que fica a aproximadamente $24 \mathrm{~km}$ de distância. O município mantém um convênio com essa instituição pelo repasse de verbas, além de ofertar o transporte diário de ida e volta para esses alunos. Os demais alunos com deficiência ${ }^{5}$ são matriculados na rede regular de ensino da própria cidade.

Para os alunos matriculados na rede regular, com deficiência ou qualquer tipo de dificuldade escolar, o município disponibiliza um serviço de terapia ocupacional. Os

\footnotetext{
${ }^{5}$ De acordo com a terapeuta ocupacional, são atendidos alunos com deficiência intelectual, com baixa visão, atrasos mentais e/ou atrasos cognitivos. Os casos mais comuns são os de alunos com deficiências intelectuais, dificuldades de aprendizagem, atrasos cognitivos e atrasos globais de desenvolvimento psicomotor. Também existem os casos de alunos com síndromes específicas, como a Síndrome Moebius, as anomalias que comprometem a linguagem e outros aspectos, os de atrasos no desenvolvimento neuropsicomotor (DNPM), microcefalia, hidrocefalia e paralisia cerebral.
} 
DOI: $10.5902 / 198468628212$

encaminhamentos para esse serviço são feitos pela direção da escola em que estão matriculados, a pedido dos professores ou de profissionais da área da saúde que atuam na educação, como psicólogos, fonoaudiólogos, pediatras, psiquiatras e neurologistas. Os atendimentos de terapia ocupacional ocorrem no contraturno das aulas regulares. Esse serviço fica localizado no prédio da Secretaria Municipal de Educação do município. No local é disponibilizada uma sala para os atendimentos com as crianças e jovens, que geralmente são acompanhados pelos pais e ou responsáveis.

Conforme relato da terapeuta ocupacional, ao todo, são atendidas 30 crianças e jovens com idades que variam de 4 a 14 anos. Semanalmente, são realizados atendimentos individuais, com 50 minutos de duração, com dias e horários fixos, em que são trabalhados aspectos como atenção, concentração, raciocínio lógico, memória, coordenação motora fina, coordenação viso-motora e também aspectos cognitivos e de linguagem assim como habilidades relacionadas à leitura e à escrita. Todos esses aspectos são avaliados e tratados por meio de técnicas e métodos baseados no brincar, em atividades psicomotoras e em estimulação cognitiva.

Com esse panorama em mãos, a próxima etapa foi analisar as matrículas de alunos com deficiência no município.

\section{Caminhos metodológicos}

Segundo Gatti (2006), poucos estudos em ciências humanas utilizam como método a abordagem quantitativa, principalmente na área da pesquisa educacional. A autora constatou que há mais de duas décadas não são contemplados estudos disciplinares sobre quantificação na formação de docentes, mestres e doutores em educação, pois os educadores encontram dificuldades em trabalhar com bases de dados, medidas, análises estatísticas, mensurações, entre outros. Essas dificuldades apresentadas pelos pesquisadores da área educacional edificaram, ao longo do tempo, preconceitos com a metodologia de pesquisa quantitativa.

Evangelista (2012) mostra que os documentos de política nacional, dentre eles dados do censo escolar, expressam a história e as condições vivenciadas pelo homem na educação brasileira. Nas palavras da autora, “(...) documento é história. Não é possível qualquer investigação que passe ao largo dos projetos históricos que expressa (...)" (2012, p.3). 


\section{DOI: $10.5902 / 198468628212$}

No que se refere ao método, Ferraro (2012) propõe a unidade entre a pesquisa qualitativa e quantitativa na educação. Com essa compreensão, enfrentamos o desafio proposto pelo autor, de analisar os dados do censo escolar de matrículas de alunos com deficiência com um olhar a partir da realidade educacional do município paulista.

Segundo o site do Instituto Nacional de Estudos e Pesquisas Educacionais Anísio Teixeira $(\operatorname{Inep})^{6}$, o censo escolar é realizado conforme prevê a legislação, que regula os levantamentos das estatísticas educacionais nacionais e segue, portanto, uma obrigatoriedade quanto à declaração das informações. Isso garante o caráter confidencial das informações coletadas e prevê a divulgação ${ }^{7}$ e a entrega de resultados à sociedade.

O Decreto no 6.425 , de 4 de abril de 2008, que dispõe sobre o censo anual da educação, afirma,

§ 10 As autoridades do Poder Executivo dos Estados, do Distrito Federal e dos Municípios, de acordo com suas respectivas competências, são responsáveis pela exatidão e fidedignidade das informações prestadas para o censo escolar (BRASIL, 2008a, s/n).

O censo escolar apresenta quatro bancos de dados: turma, escola, docente e matrículas. Neste estudo, o foco foi no banco de dados de matrículas do censo escolar e foram agregados segundo as variáveis ${ }^{8}$ : tipo de deficiência (visual, auditiva, física e mental), código de identificação única ${ }^{9}$, idade e etapa de ensino ${ }^{10}$.

O ano de 2007 foi delimitado como período inicial da análise do censo escolar por ter sido anterior ao estabelecimento da Política Nacional de Educação Especial na Perspectiva da Educação Inclusiva Brasil (BRASIL, 2008a), implantada pela Secretaria de Educação Especial do Ministério da Educação, em 2008. O último ano analisado foi 2011, por apresentar os dados mais atuais no momento da realização deste estudo (BRASIL, 2011).

Para a execução desse trabalho, primeiro identificamos a quantidade de matrículas de alunos com deficiência no município. Em seguida, para traçar o fluxo escolar desses alunos, selecionamos o código de identificação de cada um e verificarmos, no período de

\footnotetext{
6 Informação do site do Inep. Disponível em: <http://portal.inep.gov.br/basica-censo/legislacao-edocumentos>. Acesso em 02 dez. 2016.

7 Os dados referentes ao censo escolar se encontram no site do Inep para download e necessitam de softwares específicos para a leitura dos dados. Neste estudo, para leitura e tratamento estatístico dos microdados da Educação Básica, utilizou-se o Software IBM SPSS (Statistical Package for the Social Sciences).

${ }^{8}$ As nomenclaturas das variáveis estão de acordo com o caderno de instruções do Inep, 2011a.

${ }^{9}$ Código de identificação do aluno gerado pelo Inep.

10 São categorias em que as modalidades são oferecidas: Educação Infantil (creche e pré-escola, alunos até seis anos), Ensino Fundamental (alunos da $1^{\underline{a}}$ a $8^{\underline{a}}$ serie e do $1^{\circ}$ ao $9^{\circ}$ ano), Ensino Médio e Educação de Jovens e Adultos (Inep, Caderno de Instruções, 2011a).
} 
DOI: $10.5902 / 198468628212$

2007 a 2011, o movimento dessas matrículas, ou seja, analisou-se, ano a ano, em que série/etapa de ensino o aluno estava ou que deveria estar matriculado. Destacamos que esse processo de coleta de dados é minucioso, pois exige uma análise singular sobre a matrícula de cada aluno com deficiência no município em questão.

\section{Resultados e discussão}

A figura 1 mostra a tendência das matrículas de alunos com deficiência ${ }^{11}$ na educação básica na região Sudeste e no estado de São Paulo.

Figura 1 - Tendência das matrículas de alunos com deficiência na região Sudeste e no estado de São Paulo na educação básica.

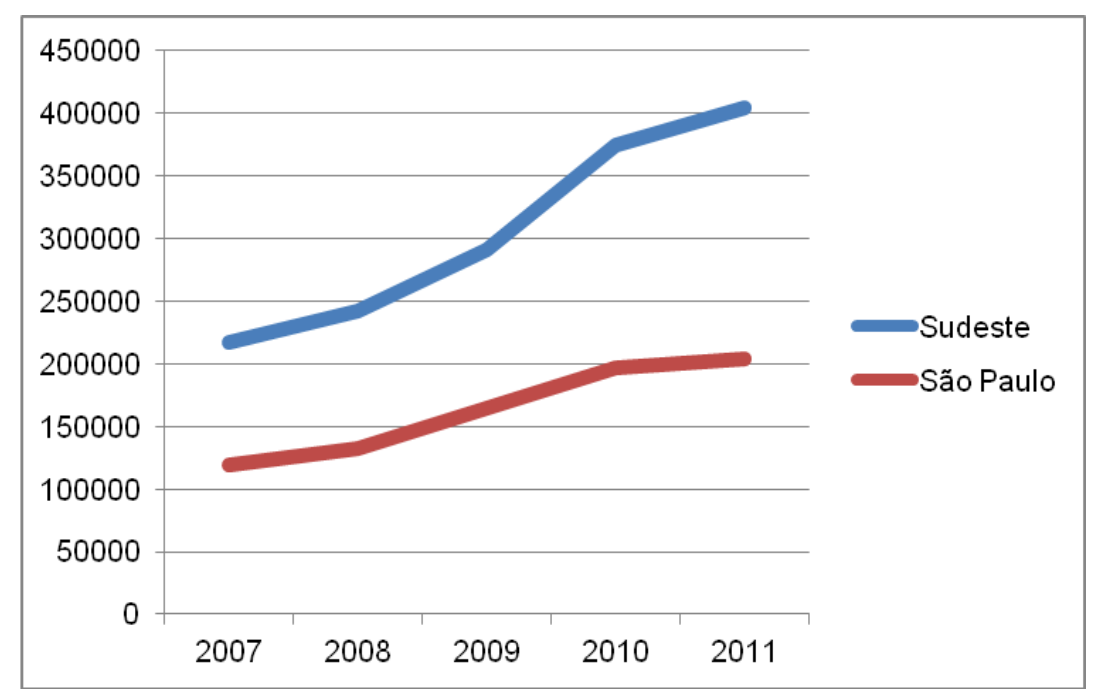

Fonte:

Elaboração

das autoras com base no Censo Escolar da Educação Básica: microdados, INEP (2007, 2008,

2009, 2010, 2011)

Merece destaque o aumento contínuo de matrículas de alunos com deficiência ${ }^{12}$ na região Sudeste e no estado de São Paulo. Esse dado representa um avanço como direito social. Por outro lado, questiona-se sobre a oferta desse atendimento na região Sudeste e no estado de São Paulo. Qual dependência administrativa (pública ou privada) está atendendo essa população? Como está sendo realizado esse atendimento, no que diz respeito aos conhecimentos científicos produzidos pelo homem?

11 Refere-se à soma das matrículas com deficiência visual, auditiva, física e mental.

12 Esses dados, de alunos com deficiência, apresentam o número total, que inclui a dupla matrícula estimulada pelo governo federal para a distribuição de recursos financeiros conforme citado na LDBEN (BRASIL, 1996). 
DOI: $10.5902 / 198468628212$

No município estudado, os dados de matrículas de alunos com deficiência no ensino regular variaram ano a ano, no período de 2007 a 2011, conforme mostra a figura 2.

Figura 2- Tendência das matrículas de alunos com deficiência no município paulista.

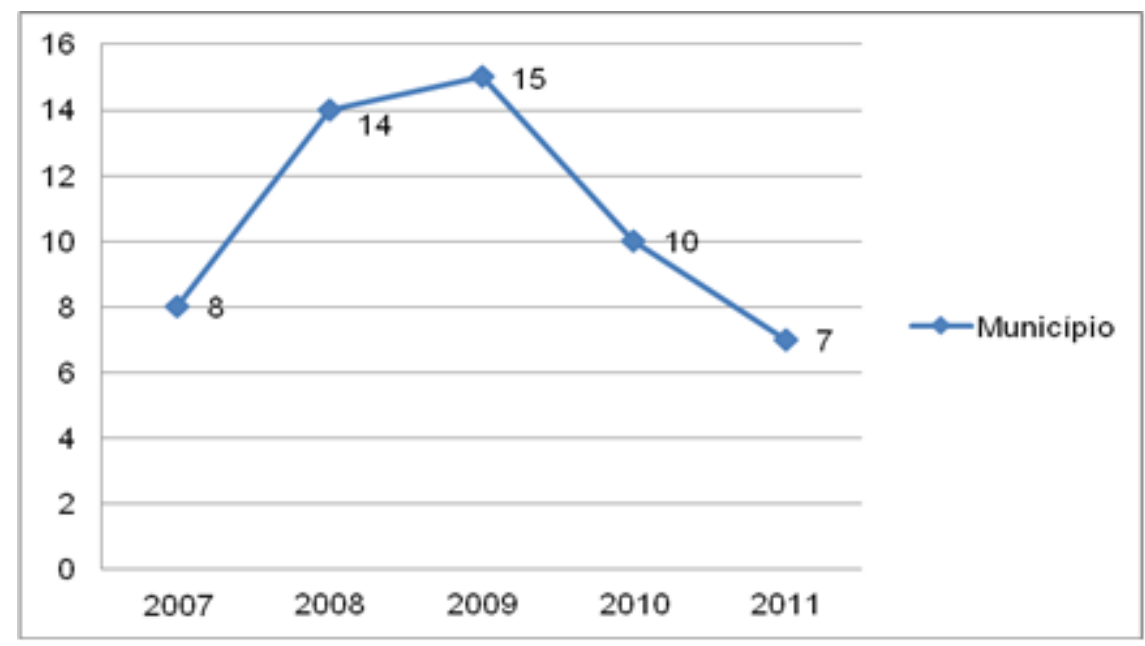

Fonte: Elaboração das autoras com base no Censo Escolar da Educação Básica: microdados, $\operatorname{INEP}(2007,2008,2009,2010,2011)$.

Os dados revelam que grande parte dos alunos com deficiência não tiveram acesso ao conhecimento escolar, ou apresentaram um fluxo escolar interrompido. Desse modo, por não lhes ser garantido o direito de estudar na idade escolar, restará a eles a Educação de Jovens e Adultos (EJA). Os índices de matrícula no ensino fundamental mostram que a maioria da população tem o acesso garantido, porém isso

(...) não garante a todos os alunos a permanência e a progressão no sistema escolar, produzindo adicionalmente demandas crescentes na modalidade Educação de Jovens e Adultos, por parte daqueles que não puderam completar sua escolarização com idades mais adequadas. (LAVARSE; MAINARDES, 2010, p.2).

Outra situação preocupante é a defasagem idade-série das matrículas de alunos com deficiência no município, também indicada no estudo de Meletti e Ribeiro (2014) ao analisarem a relação idade-série dos alunos com necessidades educacionais especiais (NEE) ${ }^{13}$ da educação básica brasileira no ano de 2012. As autoras concluíram que $13,19 \%$ dos alunos com NEE estavam com idade adequada à série; $22,67 \%$ estavam com defasagem de um ano e $64,14 \%$ apresentavam grande defasagem (dois anos ou mais) em relação à série/ano que deveriam frequentar.

\footnotetext{
${ }^{13}$ Estudantes com deficiência, transtornos globais do desenvolvimento ou altas habilidades/superdotação (Caderno de instruções, Inep, 2011a).
} 
DOI: $10.5902 / 198468628212$

Como o município estudado é de pequeno porte, temos a possibilidade de identificar cada aluno cadastrado no Censo Escolar e analisar, a partir de um trabalho minucioso, seu fluxo escolar. Inicialmente, selecionamos o código do município, de acordo com o número disponibilizado pelo endereço eletrônico do Instituto Brasileiro de Geografia e Estatística (IBGE). Em seguida, mapeamos, no município, a quantidade de matrículas de alunos com NEE e o código dessas matrículas. Posteriormente, selecionamos individualmente cada matrícula com o respectivo código por ano (2007 a 2011). Com o isolamento de cada matrícula, tínhamos dados específicos - idade e etapa de ensino -, o que nos possibilitou acompanhar o fluxo escolar desses alunos.

Diante disso, verificaremos o fluxo escolar dos alunos com deficiência no município segundo a idade e etapa de ensino, conforme demonstra a tabela 1.

Tabela 1- Fluxo escolar dos alunos com deficiência segundo a etapa do ensino regular e a idade

\begin{tabular}{|c|c|c|c|c|c|}
\hline \multirow[t]{2}{*}{ Aluno e deficiência } & \multicolumn{5}{|c|}{ Anos } \\
\hline & 2007 & 2008 & 2009 & 2010 & 2011 \\
\hline 01 - Def. Visual & $\begin{array}{l}\text { Ens. Médio: } \\
1^{\text {a }} \text { série } \\
16 \text { anos }\end{array}$ & $\begin{array}{l}\text { Ens. Médio: } \\
1^{\text {a }} \text { série } \\
17 \text { anos }\end{array}$ & - & - & - \\
\hline 02 - Def. Auditiva & $\begin{array}{l}\text { Ens. Fund. } \\
8 \text { anos: } \\
5^{\text {a }} \text { série } \\
14 \text { anos }\end{array}$ & $\begin{array}{l}\text { Ens. Fund. } 8 \\
\text { anos: } \\
6^{\text {a }} \text { série } \\
15 \text { anos }\end{array}$ & $\begin{array}{l}\text { Ens. Fund. } \\
9 \text { anos: } \\
8^{\circ} \text { ano } \\
16 \text { anos }\end{array}$ & - & $\begin{array}{l}\text { Ens. Médio: } \\
1 \text { a série } \\
18 \text { anos }\end{array}$ \\
\hline 03 - Def. Auditiva & $\begin{array}{l}\text { Ens. Fund. } \\
8 \text { anos } \\
5^{\text {a }} \text { série } \\
16 \text { anos }\end{array}$ & $\begin{array}{l}\text { Ens. Fund. } 8 \\
\text { anos } \\
6^{\underline{a}} \text { série } \\
17 \text { anos }\end{array}$ & $\begin{array}{l}\text { Ens. Fund. } \\
9 \text { anos } \\
7^{\text {a }} \text { série } \\
18 \text { anos }\end{array}$ & - & - \\
\hline 04 - Def. Visual & $\begin{array}{l}\text { Ens. Médio } \\
1^{\text {a }} \text { série } \\
17 \text { anos }\end{array}$ & $\begin{array}{l}\text { Ens. Médio } \\
2^{a} \text { série } \\
18 \text { anos }\end{array}$ & $\begin{array}{l}\text { EJA Pres. } \\
\text { Ens. Médio } \\
19 \text { anos }\end{array}$ & - & - \\
\hline 05 - Def. Auditiva & $\begin{array}{l}\text { Ens. Médio } \\
1^{\text {a }} \text { série }\end{array}$ & $\begin{array}{l}\text { Ens. Médio } \\
2^{\underline{a}} \text { série }\end{array}$ & $\begin{array}{l}\text { Ens. Médio } \\
3^{\text {a }} \text { série }\end{array}$ & - & - \\
\hline
\end{tabular}


DOI: $10.5902 / 198468628212$

\begin{tabular}{|c|c|c|c|c|c|}
\hline & 15 anos & 16 anos & 17 anos & & \\
\hline 06 - Def. Visual & $\begin{array}{l}\text { Ens. Médio } \\
1^{\text {a }} \text { série } \\
15 \text { anos }\end{array}$ & $\begin{array}{l}\text { Ens. Médio } \\
2^{\underline{a}} \text { série } \\
16 \text { anos }\end{array}$ & - & - & - \\
\hline 07 - Def. Mental & $\begin{array}{l}\text { Ens. Fund. } \\
8 \text { anos } \\
4^{a} \text { série } \\
11 \text { anos }\end{array}$ & - & - & - & - \\
\hline 08 - Def. Visual & $\begin{array}{l}\text { EJA Pres. } \\
\text { Médio } \\
26 \text { anos }\end{array}$ & - & - & - & - \\
\hline 09- Def. Mental & - & $\begin{array}{l}\text { Ens. Fund } \\
8 \text { anos } \\
4^{\text {a }} \text { série } \\
15 \text { anos }\end{array}$ & - & - & - \\
\hline 10 - Def. Mental & - & $\begin{array}{l}\text { Ens. Fund } \\
8 \text { anos } \\
2^{\underline{a}} \text { série } \\
10 \text { anos }\end{array}$ & $\begin{array}{l}\text { Ens. Fund. } \\
9 \text { anos } \\
4^{\circ} \text { ano } \\
11 \text { anos }\end{array}$ & - & - \\
\hline 11- Def. Mental & - & $\begin{array}{l}\text { Ens. Fund } \\
8 \text { anos } \\
4^{\text {a }} \text { série } \\
13 \text { anos }\end{array}$ & $\begin{array}{l}\text { Ens. Fund. } \\
9 \text { anos } \\
\text { 6 ano } \\
14 \text { anos }\end{array}$ & $\begin{array}{l}\text { Ens. } \\
\text { Fund. } 9 \\
\text { anos } \\
7^{\circ} \text { ano } \\
15 \text { anos }\end{array}$ & $\begin{array}{l}\text { Ens. Fund } \\
9 \text { anos } \\
8^{a} \text { ano } \\
16 \text { anos }\end{array}$ \\
\hline 12 - Def. Mental & - & $\begin{array}{l}\text { Ens. Fund } \\
8 \text { anos } \\
1^{\text {a }} \text { série } \\
9 \text { anos }\end{array}$ & $\begin{array}{l}\text { Ens. Fund. } \\
9 \text { anos } \\
3^{\circ} \text { ano } \\
10 \text { anos }\end{array}$ & $\begin{array}{l}\text { Ens. Fund. } \\
9 \text { anos } \\
4^{\circ} \text { ano } \\
11 \text { anos }\end{array}$ & - \\
\hline 13 - Def. Mental & - & $\begin{array}{l}\text { Ens. Fund. } \\
8 \text { anos } \\
2^{2} \text { série } \\
8 \text { anos }\end{array}$ & $\begin{array}{l}\text { Ens. Fund. } \\
9 \text { anos } \\
\text { 3o ano } \\
9 \text { anos }\end{array}$ & - & - \\
\hline 14- Def. Mental & & $\begin{array}{l}\text { Ens. Fund. } \\
8 \text { anos }\end{array}$ & $\begin{array}{l}\text { Ens. Fund. } \\
9 \text { anos }\end{array}$ & $\begin{array}{l}\text { Ens. Fund. } \\
9 \text { anos }\end{array}$ & $\begin{array}{l}\text { Ens. Fund } \\
9 \text { anos }\end{array}$ \\
\hline
\end{tabular}


DOI: $10.5902 / 198468628212$

\begin{tabular}{|c|c|c|c|c|c|}
\hline & - & $\begin{array}{l}2^{a} \text { série } \\
10 \text { anos }\end{array}$ & $\begin{array}{l}4^{\circ} \text { ano } \\
11 \text { anos }\end{array}$ & $\begin{array}{l}5^{\circ} \text { ano } \\
12 \text { anos }\end{array}$ & $\begin{array}{l}6^{\circ} \text { ano } \\
13 \text { anos }\end{array}$ \\
\hline 15 - Def. Visual & - & $\begin{array}{l}\text { Ens. Fund. } \\
8 \text { anos } \\
1^{\text {a }} \text { série } \\
8 \text { anos }\end{array}$ & $\begin{array}{l}\text { Ens. Fund. } \\
9 \text { anos } \\
3^{\circ} \text { ano } \\
9 \text { anos }\end{array}$ & $\begin{array}{l}\text { Ens. Fund. } \\
9 \text { anos } \\
4^{\circ} \text { ano } \\
10 \text { anos }\end{array}$ & $\begin{array}{l}\text { Ens. Fund } \\
9 \text { anos } \\
4^{\circ} \text { ano } \\
11 \text { anos }\end{array}$ \\
\hline 16 - Def. Física & - & $\begin{array}{l}\text { Ens. Fund. } \\
8 \text { anos } \\
1^{\text {a }} \text { série } \\
8 \text { anos }\end{array}$ & $\begin{array}{l}\text { Ens. Fund. } \\
9 \text { anos } \\
2^{\circ} \text { ano } \\
9 \text { anos }\end{array}$ & $\begin{array}{l}\text { Ens. Fund. } \\
9 \text { anos } \\
3^{\circ} \text { ano } \\
10 \text { anos }\end{array}$ & $\begin{array}{l}\text { Ens. Fund } \\
9 \text { anos } \\
3^{\circ} \text { ano } \\
11 \text { anos }\end{array}$ \\
\hline 17 - Def. Auditiva & - & - & $\begin{array}{l}\text { Ens. Fund. } \\
9 \text { anos } \\
1^{\circ} \text { ano } \\
7 \text { anos }\end{array}$ & $\begin{array}{l}\text { Ens. Fund. } \\
9 \text { anos } \\
2^{\circ} \text { ano } \\
8 \text { anos }\end{array}$ & $\begin{array}{l}\text { Ens. Fund } \\
9 \text { anos } \\
3^{\circ} \text { ano } \\
9 \text { anos }\end{array}$ \\
\hline 18 - Def. Mental & - & - & $\begin{array}{l}\text { Ens. Fund. } \\
9 \text { anos } \\
2^{\circ} \text { ano } \\
10 \text { anos }\end{array}$ & $\begin{array}{l}\text { Ens. Fund. } \\
9 \text { anos } \\
3^{\circ} \text { ano } \\
11 \text { anos }\end{array}$ & $\begin{array}{l}\text { Ens. Fund. } \\
9 \text { anos } \\
4^{\circ} \text { ano } \\
12 \text { anos }\end{array}$ \\
\hline 19 - Def. Visual & - & - & $\begin{array}{l}\text { Ens. Fund. } \\
9 \text { anos } \\
7^{\circ} \text { ano } \\
18 \text { anos }\end{array}$ & - & - \\
\hline 20- Def. Mental & - & - & $\begin{array}{l}\text { EJA Pres. } \\
1^{\text {a }} \text { a } 4^{\underline{a}} \\
\text { série } \\
23 \text { anos }\end{array}$ & - & - \\
\hline 21 - Def. Física & - & - & - & $\begin{array}{l}\text { Ens. Médio } \\
\text { 3ª série } \\
19 \text { anos }\end{array}$ & - \\
\hline 22 - Def. Física & - & - & - & $\begin{array}{l}\text { Ens. Médio } \\
3^{\text {a }} \text { série } \\
18 \text { anos }\end{array}$ & - \\
\hline
\end{tabular}


DOI: $10.5902 / 198468628212$

\begin{tabular}{|l|l|l|l|l|l|}
\hline $23-$ Def. Mental & & & & & Ens. Fund. \\
9 anos & \\
$5^{\circ}$ ano & \\
12 anos & - \\
\hline
\end{tabular}

Fonte: Elaboração das autoras com base no Censo Escolar da Educação Básica: microdados, INEP (2007, 2008, 2009, 2010, 2011 e 2012).

Do total $(n=23)$ de alunos com deficiência, 11 (48\%) evadiram (do ensino fundamental e médio), 6 (26\%) chegaram ao ensino médio (parecem ter concluído ou estão cursando), e $6(26 \%)$ estavam matriculados no ensino fundamental no ano de 2011. Para Ferraro (1999, p. 46), o problema mais grave das escolas brasileiras permanece sendo a exclusão na escola, com mecanismos de reprovação e repetência que resultam na evasão.

Com a operacionalização do Programa "Educação Inclusiva: Direito à Diversidade", esperava-se "obter a formação de gestores e educadores do município polo e dos municípios de abrangência efetivando assim, a proposta de educação inclusiva" (BRASIL, 2005, p.24). Entretanto, os dados de matrículas de alunos com deficiência do município analisado revelam uma descontinuidade no fluxo escolar.

Verificamos que, no município, no período da pesquisa, havia seis $(26,1 \%)$ alunos com deficiência visual; quatro $(17,4 \%)$ alunos com deficiência auditiva; três alunos com deficiência física (13\%) e dez (43,5\%) alunos com deficiência mental. Essa concentração de matrículas com deficiência mental precisa ser analisada com reserva e criticidade.

Não podemos desconsiderar a crescente medicalização do ensino (FÓRUM, 2015), as justificativas do não aprender centradas apenas no aluno e a precariedade dos processos de avaliação, de diagnóstico e de encaminhamentos pedagógicos (PATTO, 2001). Esse processo de patologização do fracasso escolar pode resultar em alunos cadastrados sob suspeitas de deficiência intelectual ou mental.

Há indícios de que a vinda de alunos público-alvo da Educação Especial na EJA esteja ocorrendo de maneira mais acentuada nos últimos anos, em decorrência da ampliação do acesso para estas pessoas no ensino regular de maneira geral (SIEMS, 2011). 
DOI: $10.5902 / 198468628212$

Embora a EJA seja uma alternativa de inclusão escolar da população jovem e adulta público-alvo da Educação Especial, esses dados expressam a baixa qualidade do ensino básico (regular e especial), uma vez que muitos desses alunos frequentaram o ensino fundamental por muitos anos, contudo não se apropriaram dos conteúdos escolares compatíveis com os níveis de escolaridade alcançados.

Outro aspecto é a concepção e o aumento da EJA especial dentro das escolas regulares e em instituições especializadas (GONÇALVES, BUENO, MELETTI, 2013; HAAS, GONÇALVES, 2015; PLETSCH, 2012). Cabe, aqui, questionarmos como se constitui essa EJA especial e, ao mesmo tempo, verificar a trajetória escolar dos alunos que frequentam essa modalidade de ensino, uma vez que a EJA especial pode representar um retrocesso ao renegar a educação em idade regular. Esses dados assinalam que a EJA, em vez de compensar uma dívida educacional do Estado brasileiro (FERRARO, 2008), fortalece-se abarcando as falhas de escolarização na educação básica.

Deste modo, verifica-se que a realidade concreta sobre o processo de escolarização das pessoas com deficiência precisa ser mais discutida nas produções científicas acadêmicas brasileiras. Para que esse quadro se altere, é necessário que pesquisas rompam com esse silêncio e problematizem as dificuldades enfrentadas pelas pessoas com deficiência em seu processo de escolarização, pois, atualmente, ainda há muitas pessoas com deficiência sem o direito à escola e ao atendimento educacional especializado, apesar do que preconizam os documentos e as políticas públicas do país.

\section{Considerações finais}

Esse estudo inicial investigou um único município de abrangência, de pequeno porte, que participou do Programa "Educação Inclusiva: Direito à Diversidade". Baseando-se nos microdados do Inep, que apresentam os indicadores da educação brasileira, os resultados mostram as taxas de transição dos alunos com deficiência do município.

Materializa-se que a apropriação do conhecimento escolar ainda é um privilégio para poucos, devido à enorme desigualdade social em nosso país. Ao tratar da educação escolar para as pessoas com deficiência, verificamos, nesse pequeno município paulista, o quanto 


\section{DOI: $10.5902 / 198468628212$}

é preciso avançar em questões preliminares, tais como permanência e frequência. Entretanto, isso não é suficiente para a apropriação do conhecimento escolar.

Assumimos que todos os alunos, com e sem deficiência, têm o direito de aprender e de se apropriar da riqueza intelectual, em uma escola pública, laica e gratuita, que proporcione a socialização do conhecimento científico, filosófico e artístico (DUARTE, 2006).

Com relação à implementação do Programa "Educação Inclusiva: Direito à Diversidade" e seus desdobramentos no município, os dados indicam altos índices de defasagem idade-série, além da repetência e da evasão de alunos cadastrados como alunos com deficiência no período deste estudo. Desse modo, podemos afirmar que, neste município, o Programa não atingiu seu objetivo, qual seja, "a garantia do direito dos alunos com necessidades educacionais especiais de acesso e permanência, com qualidade, nas escolas regulares" (BRASIL, 2005, p.9).

Por fim, é importante destacar que este estudo inicial incentivou um novo projeto para a Educação Especial no município, com a iniciativa pública de implementar um Centro de Atendimento Educacional Especializado para todos os alunos público-alvo da Educação Especial que estão na rede regular de ensino. É, sem dúvida, uma iniciativa promissora, desde que, além de garantir o ingresso e a permanência nas classes comuns de ensino, também assuma o compromisso com a escolarização e com o desenvolvimento humano pleno dos alunos.

\section{Agradecimento}

Ao Observatório da Educação- CAPES pelo financiamento.

\section{Referências}

ALAVARSE, Ocimar Munhoz; MAINARDES, Jefferson. Fluxo escolar. In: OLIVEIRA, Dalila Andrade; DUARTE, Adriana Cancella; VIEIRA, Lívia Fraga (Org.). Dicionário de trabalho, profissão e condição docente. Belo Horizonte: FAE-UFMG, 2010, p.01-04. 
DOI: $10.5902 / 198468628212$

BRASIL. Lei no 9.394, de 20 de dezembro de 1996. Estabelece as Diretrizes e Bases da Educação Nacional. 1996.

MEC. SEESP. Educação Inclusiva: Direito à Diversidade. Documento orientador. Brasília, 2005.

Decreto no 6.425 de 4 de abril de 2008a. Dispõe sobre o censo anual da educação. 2008.

Ministério da Educação. Política Nacional de Educação Especial na Perspectiva da Educação Inclusiva. Brasília: MEC, 2008b. Disponível em <http://www.mec.gov.br> Acesso em: jul. 2016.

Decreto 6.949, de 25 de agosto de 2009. Promulga a Convenção Internacional sobre os Direitos das Pessoas com Deficiência e seu Protocolo Facultativo, assinados em Nova York, em 30 de março de 2007. Diário Oficial da União, Brasília, DF, 26 ago. 2009. Disponível em: <http:/www.planalto.gov.br/ccivil_03/_ato20072010/2009/decreto/d6949.htm>. Acesso em: mai. 2015.

Instituto Nacional de Estudos e Pesquisas Educacionais Anísio Teixeira - INEP (2007). Censo Escolar da Educação Básica - 2007. 2007. Disponível em: <http://www.inep.gov.br/basica/levantamentos/microdados.asp>. Acesso em: dez. 2013.

Ministério da Educação. Política Nacional de Educação Especial na Perspectiva da Educação Inclusiva. Brasília: MEC, 2008a. Disponível em <http://www.mec.gov.br> Acesso em: abr. 2015.

Instituto Nacional de Estudos e Pesquisas Educacionais Anísio Teixeira - INEP (2008b). Censo Escolar da Educação Básica - 2008. 2008. Disponível em: <http://www.inep.gov.br/basica/levantamentos/microdados.asp>. Acesso em: dez., 2013.

Instituto Nacional de Estudos e Pesquisas Educacionais Anísio Teixeira - INEP (2009). Censo Escolar da Educação Básica - 2009. 2009. Disponível em: <http://www.inep.gov.br/basica/levantamentos/microdados.asp>. Acesso em: dez. 2013.

Instituto Nacional de Estudos e Pesquisas Educacionais Anísio Teixeira - INEP (2010). Censo Escolar da Educação Básica - 2010. 2010. Disponível em: <http://www.inep.gov.br/basica/levantamentos/microdados.asp>. Acesso em: jan. 2014.

Instituto Nacional de Estudos e Pesquisas Educacionais Anísio Teixeira - INEP. Caderno de instruções - 2011a. 2011. Disponível em: <http://portal.inep.gov.br/basica-censoescolar-questionarios>. Acesso em: jan. 2014. 
DOI: $10.5902 / 198468628212$

Instituto Nacional de Estudos e Pesquisas Educacionais Anísio Teixeira - INEP (2011). Censo Escolar da Educação Básica - 2011b. 2011. Disponível em: <http://www.inep.gov.br/basica/levantamentos/microdados.asp> Acesso em: jan. 2014.

Instituto Nacional de Estudos e Pesquisas Educacionais Anísio Teixeira - INEP (2012). Censo Escolar da Educação Básica - 2012. Disponível em: <http://www.inep.gov.br/basica/levantamentos/microdados.asp> Acesso em: jan. 2014.

Instituto Nacional de Estudos e Pesquisas Educacionais Anísio Teixeira. Data Escola Brasil. Disponível em: <http://www. dataescolabrasil.INEP.gov.br>. Acesso em: jul. 2012.

CAIADO, Kátia Regina Moreno; LAPLANE, Adriana Lia Friszman. Programa Educação Inclusiva: Direito à Diversidade - uma análise a partir da visão de gestores de um município pólo. Educação e Pesquisa (USP. Impresso), São Paulo, v. 35, n. 2, p. 303-315, mai./ago, 2009.

CONFERÊNCIA MUNDIAL DE EDUCAÇÃO ESPECIAL, 1994, Salamanca. Declaração de Salamanca e linha de ação sobre necessidades educativas especiais. Brasília, DF: Corde, 1994.

DUARTE, Newton. A pesquisa e a formação de intelectuais críticos na Pós-graduação em Educação. Perspectiva, Florianópolis, v. 24, n. 1, p. 89-110, jan./ jun., 2006. Disponível em: <https://periodicos.ufsc.br/index.php/perspectiva/article/view/10313/9574>. Acesso em: fev. 2018.

EVANGELISTA, Olinda. Apontamentos para o trabalho com documentos de política educacional. In: ARAÚJO, Ronaldo Marcos de Lima; RODRIGUES, Doriedson S. (Org.). A pesquisa em trabalho, educação e políticas educacionais. Campinas, SP: Alínea, 2012. p. 52-71.

FERRARO, Alceu Ravanello. Direito à Educação no Brasil e dívida educacional: e se o povo cobrasse? Educação e Pesquisa (USP. Impresso), São Paulo, v. 34, n. 2, p. 273-289, mai./ ago., 2008.

Diagnóstico da escolarização no Brasil. Revista Brasileira de Educação, Rio de Janeiro, n. 12, p. 22-47, set./dez., 1999.

Quantidade e qualidade na pesquisa em educação, na perspectiva da dialética marxista. Pro-Posições, Campinas, v. 23, n.1 (67), p.129-146, jan./abr., 2012.

FÓRUM SOBRE MEDICALIZAÇÃO DA EDUCAÇÃO E DA SOCIEDADE. Disponível em: $<$ http://medicalizacao.org.br> Acesso em: set. 2015. 
DOI: $10.5902 / 198468628212$

GATTI, Bernadete Angelina. Pesquisar em educação: considerações sobre alguns pontoschave. Revista Diálogo Educacional, Curitiba, v. 6, n. 19, p. 25-35, set./dez. 2006. Disponível

em:

$<$ http://www2.pucpr.br/reol/pb/index.php/dialogo?dd1=235\&dd99=view\&dd98=pb> Acesso em: fev. 2018.

GONÇALVES, Taísa Grasiela Gomes Liduenha; BUENO, José Geraldo Silveira Bueno; MELETTI, Silvia Márcia Ferreira. Matrículas de alunos com deficiência na EJA: Uma análise dos indicadores educacionais brasileiros. Revista Brasileira de Política e Administração da Educação, Goiânia, v. 29, n.3, p. 407-427, set./ dez., 2013. Disponível em: < http://seer.ufrgs.br/index.php/rbpae/article/view/47212/29417> . Acesso em: fev. 2018.

HAAS, Clarissa; GONÇALVES, Taísa Grasiela Gomes Liduenha. Em tempos de democratização do direito à educação: como têm se delineado as políticas de acesso à EJA aos estudantes com deficiência no Rio Grande do Sul? Revista Brasileira de Educação Especial, Marília, v. 21, n.4, p. 443-458, 2015. Disponível em: $<$ http://www.scielo.br/scielo.php?pid=S1413-

65382015000400443\&script=sci_abstract\&tlng=pt> Acesso em: fev. 2018.

IBGE. SIDRA. Sistema IBGE de Recuperação Automática. Brasília, 2010. Disponível em: <http://www.sidra.ibge.gov.br>. Acesso em: mar. 2015.

MELETTI, Silvia Márcia Ferreira; RIBEIRO, Karen. Indicadores educacionais sobre a educação especial no Brasil. Cadernos CEDES, Campinas, v. 34, n. 93, p. 175-189, 2014. Disponível em: <http://www.scielo.br/scielo.php?pid=S010132622014000200175\&script=sci_abstract\&tlng=pt> . Acesso em: fev. 2018.

OBSERVATÓRIO DO PNE, 2013. Disponível em: <http://www.observatoriodopne.org.br>. Acesso em: jul. 2017.

PATTO, Maria Helena Souza. A produção do fracasso escolar: histórias de submissão e rebeldia. 2. ed. São Paulo: Casa do Psicólogo, 2001.

PLETSCH, Márcia Denise. Uma análise sobre o atendimento educacional especializado: políticas, práticas e formação de professores. Intermeio (UFMS), v. 18, n.36, p. 150-161, jul./dez., 2012.

Disponível em: <http://www.seer.ufms.br/index.php/intm/article/view/2379/1493> Acesso em: fev. 2018.

PNUD/IPEA/FJP. Atlas de desenvolvimento humano no Brasil. Brasília, 2013. Disponível em: <http://www.atlasbrasil.org.br>. Acesso em: nov. 2013. 
DOI: $10.5902 / 198468628212$

SIEMS, Maria Edith Romano. Educação de jovens e adultos com deficiência: saberes e caminhos em construção. Educação em Foco, Juiz de Fora, v. 16, n. 2, p. 61-79, set./fev., 2011.

\section{Correspondência}

Ana Carolina Macalli - Universidade Federal de São Carlos (UFSCar), Rodovia Washington Luís, CEP: 13565-905, São Carlos, São Paulo, Brasil.

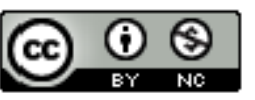

Th is work is licensed under a Creative Commons Attribution-NonCommercial 4.0 International (CC BY-NC 4.0) 